Research Paper

\title{
Osterix Controls Cementoblast Differentiation through Downregulation of Wnt-signaling via Enhancing DKK1 Expression
}

\author{
Zhengguo Cao ${ }^{1,2}, \#$, Rubing Liu ${ }^{1 \#}$, Hua Zhang 3 , Haiqing Liao', Yufeng Zhang1, Robert J. Hinton ${ }^{3}$, and \\ Jian Q. Feng ${ }^{3}$ \\ 1. The State Key Laboratory Breeding Base of Basic Science of Stomatology (Hubei-MOST KLOS) \& Key Laboratory for Oral Biomedical \\ Engineering of Ministry of Education(KLOBME), School \& Hospital of Stomatology, Wuhan University, Wuhan, China \\ 2. Department of Periodontology, School \& Hospital of Stomatology, Wuhan University, Wuhan, China \\ 3. Texas A\&M University, Baylor College of Dentistry, 3302 Gaston Avenue, Dallas, TX, USA \\ \# Both authors equally contribute to this work.
}

$\triangle$ Corresponding author: Correspondence should be addressed to Zhengguo Cao. Tel: +86-27-87686212, E-mail: jery7677@hotmail.com

๑ 2015 Ivyspring International Publisher. Reproduction is permitted for personal, noncommercial use, provided that the article is in whole, unmodified, and properly cited. See http://ivyspring.com/terms for terms and conditions.

Received: 2014.10.21; Accepted: 2014.12.19; Published: 2015.02.05

\begin{abstract}
Osterix (Osx), a transcriptional factor essential for osteogenesis, is also critical for in vivo cellular cementum formation. However, the molecular mechanism by which Osx regulates cementoblasts is largely unknown. In this study, we initially demonstrated that overexpression of Osx in a cementoblast cell line upregulated the expression of markers vital to cementogenesis such as osteopontin (OPN), osteocalcin (OCN), and bone sialoprotein (BSP) at both mRNA and protein levels, and enhanced alkaline phosphatase (ALP) activity. Unexpectedly, we demonstrated a sharp increase in the expression of DKK1 (a potent canonical Wnt antagonist), and a great reduction in protein levels of $\beta$-catenin and its nuclear translocation by overexpression of Osx. Further, transient transfection of Osx reduced protein levels of TCFI (a target transcription factor of $\beta$-catenin), which were partially reversed by an addition of DKK1. We also demonstrated that activation of canonical Wnt signaling by $\mathrm{LiCl}$ or Wnt3a significantly enhanced levels of TCFI and suppressed the expression of OPN, OCN, and BSP, as well as ALP activity and formation of extracellular mineralized nodules. Importantly, we confirmed that there were a sharp reduction in DKK 1 and a concurrent increase in $\beta$-catenin in Osx cKO mice (crossing between the Osx loxP and $2.3 \mathrm{Col}$ l-Cre lines), in agreement with the in vitro data. Thus, we conclude that the key role of Osx in control of cementoblast proliferation and differentiation is to maintain a low level of Wnt- $\beta$-catenin via direct up-regulation of DKK1.
\end{abstract}

Key words: cementum; Osterix; DKK1; cementoblast differentiation; Wnt signaling

\section{INTRODUCTION}

Human periodontitis is the most common infectious disease, and the global prevalence of severe periodontitis is more than $10 \%(1)$. Cementum, a thin layer of mineralized tissue, plays an essential role in anchoring teeth to the surrounding alveolar bone. Consequently, cementum regeneration is considered a gold standard of successful periodontal tissue recon- struction (2). Cementoblasts, the cells forming cementum, share a similar gene expression pattern to that of osteoblasts, including runt-related gene 2 (Runx2), Osx, and type I collagen (Col 1), Ocn, Opn and Bsp (3-6). However, the exact molecular mechanisms regulating cementoblast differentiation are not fully elucidated. 
Wnt signaling is critical for normal development of multicellular organisms by regulating cell proliferation, differentiation, and apoptosis (7). Activation of the canonical $W n t / \beta$-catenin signaling leads to the stabilization and accumulation of cytosolic $\beta$-catenin, which then translocates to the nucleus where it interacts with members of the LEF/TCF family of transcription factors, resulting in the transcription of Wnt-target genes $(8,9)$. Recently, dental researchers have focused on the potential role of Wnt signaling during morphogenesis of periodontal tissues. Not only are there several key Wnt-responsive cells in periodontal tissues such as osteoblasts, periodontal ligament (PDL) cells, odontoblasts, and cementoblasts, but also Wnt signaling potentially controls the proliferation and differentiation process of these cells (10-12). Wnt signaling is reported to inhibit cementoblast differentiation and promote proliferation in vitro (13). In the adult Axin2 $2^{\mathrm{LaCZ}+/-}$ incisor PDL, cells showing the highest level of Wnt responsiveness in the cementum-PDL tissue display the greatest proliferation. Conversely, cells with the lowest levels of Wnt responsiveness exhibit the greatest amount of cell differentiation (14). Sclerostin (SOST), an antagonist of Wnt, is detected in cementocytes and mineralizing PDL cells $(15,16)$, and thicker acellular and cellular cementum is observed in the sclerostin knockout mice (17). Interestingly, in individuals with VBD (van Buchem disease), SOST was either absent or greatly decreased in osteocytes and cementocytes, although this change was associated with increased bone formation, but no overt changes in cementum thickness (18).

OSX, the zinc finger-containing transcription factor, functions genetically downstream of Runx2 and down-regulates the canonical Wnt signaling pathway through activating DKK1 (a potent canonical Wnt antagonist) in osteoblasts (19-21). It has been demonstrated that $O s x$ is required for osteoblast differentiation (22-24) and postnatal cartilage formation (25). Likewise, $O s x$ is likely required for cementogenesis (6, 26). For example, Runx2 and Osx are co-localized in cementoblasts, and Osx is significantly upregulated in cementum on both compression and tension sides during orthodontic tooth movement (27). Our recent studies showed that there is a close relationship between the temporal- and spatial-expression pattern of $O s x$ and the formation of cellular cementum, and there is accelerated cementum formation in the 3.6-Col 1-Osx transgenic mouse line (26). On the other hand, conditional deletion of Osx in mesenchymal cells by crossing the $2.3 \mathrm{~kb}$ Col 1-Cre and $O s x$ loxP mice led to a sharp reduction in cellular cementum formation (including cementum mass and mineral deposition rate), although the detailed mo- lecular mechanism remains unresolved.

In this study, we attempted to address how $O s x$ controls cementoblasts using a combination of both in vitro and in vivo approaches. Our results demonstrated that $O s x$ accelerates cementoblast differentiation in part through down-regulation of the Wnt/ $\beta$-catenin signaling by activating DKK 1 . This finding sheds light on the mechanisms by which $O s x$ regulates cementoblast differentiation.

\section{MATERIALS AND METHODS}

\section{Cell cultures and Plasmid constructs}

The mouse cementoblast cell line OCCM-30 (28) was maintained in Dulbecco's Modified Eagle's Medium (DMEM) supplemented with 10\% FBS, $100 \mathrm{U} / \mathrm{ml}$ penicillin $\mathrm{G}$, and $100 \mathrm{ug} / \mathrm{ml}$ streptomycin. The cells were cultured at $37^{\circ} \mathrm{C}$ in humidified incubators with $5 \% \mathrm{CO}_{2}$ and $95 \%$ air. Osx cDNA was amplified and cloned into EcoRI and BamHI sites of pIRES2 expression vector. The sequence of Osx cDNA was confirmed by DNA sequence analysis.

\section{Mice}

Osx-lacZ (29) knock-in mice, where Osx is replaced by a lac $Z$ reporter (29), were used for tracing where Osx is expressed in the region of the PDL and cementum at the age of 6 -weeks. To avoid neonatal death, mice harboring a floxed allele of $O s x$ (30) were crossed to the 2.3 Col 1-Cre mice (31) for tissue-specific deletion of $O s x$ at the embryonic stage to cover early stage phenotype during cementogenesis. Genotyping was determined by polymerase chain reaction (PCR) analysis of genomic DNA with primers p01: 5'-CGGGGAGTCCCGAGGACTCTG-3' and p02: 5'-CTGTCTTCACCTCAATTCTATT-3' to detect the wild-type allele ( $\sim 400$ base pairs [bp]) and $O s x(\sim 550$ bp); and primers p03: 5'-CCCGCAGAACCTGAAGA TG-3' and primers p04: 5'-GACCCGGCAAAACAG GTAG-3' to detect the Cre allele ( $500 \mathrm{bp})$.

\section{Reagents and Antibodies}

Lithium chloride, ascorbic acid, $\mathrm{Na} \beta$-glycerophosphate and dexamethasone were purchased from Sigma Chemical Company (St Louis, MO, USA). Recombinant mouse DKK1 was obtained from R\&D Systems (Minneapolis, MN, USA). Alkaline phosphatase activity assay kit was purchased from Jiancheng (Nanjing, China). Antimouse rabbit antibodies to OSX, $\beta$-catenin, OCN, OPN, and ALP were obtained from Abcam (Cambridge, MA, USA). Antimouse rabbit antibody to BSP II was obtained from Santa Cruz (CA, USA). Antimouse rabbit antibody to $\beta$-actin was obtained from Good bio (Wuhan, China). 


\section{Transient transfection, siRNA interference, RNA isolation, and Real-time RT-PCR}

The OCCM-30 cells were seeded in $60 \mathrm{~mm}$ dishes in DMEM without antibiotics the day before transfection. The cells were transfected with $1 \mu \mathrm{g}$ of pIRES2-Osx plasmids or vectors with Lipofectamine 3000 according to manufacturer's instructions. In siRNA interference assay, 200 pmol Osx siRNA (5'-GGAUAUGACUCAUCCCUAUTTT- ${ }^{\prime}$ ' and $5^{\prime}$-AU AGGGAUGAGUCAUAUCCTT-3) or NC siRNA (5'-UUCUCCGAACGUGUCACGUTT-3' and 5'-ACG UGACACGUUCGGAGAATT-3') were transfected into cells using Lipofectamine 2000 according to manufacturer's instruction. At the end of each time point ( $24 \mathrm{hr}$. or $48 \mathrm{hr}$. or $72 \mathrm{hr}$.), total RNA was extracted from cementoblasts with TRIzol reagent (Invitrogen, USA) according to the manufacturer's instructions. RNA was also extracted from cells stimulated with $10 \mathrm{mM} \mathrm{LiCl}$ for $0,3,6,12,24$, and $36 \mathrm{hr}$. cDNAs were synthesized using Revert Aid ${ }^{\mathrm{TM}}$ First Strand cDNA Synthesis Kit (Fermentas, USA) according to the manufacturer's instructions. Real-time PCR was performed using the ABI 7500 system (Applied Biosystems) with SYBR® Premix Ex TaqTMII kit (TaKaRa, Japan). The amplification profile was $95^{\circ} \mathrm{C}$ for $10 \mathrm{~min}$, followed by 40 cycles at 95/5; 55/30; 72/30 [temperature $\left({ }^{\circ} \mathrm{C}\right) /$ time(s)]. The PCR primer sequences for each gene, Osx, $\beta$-catenin, Dkk1, Opn, Ocn, Bsp, Alp, Tcf 1, Gapdh, are shown in Table 1. Fold differences in gene expression were calculated according to the $\Delta \Delta \mathrm{Ct}$ method with normalization to GAPDH.

Table 1. Primer sequence used for real-time RT-PCR

\begin{tabular}{ll}
\hline gene & Primer sequences forward/reverse \\
\hline OPN & GAGGAAACCAGCCAAGGTAAG/ \\
& AAAGCAAATCACTGCCAATCTC \\
OCN & GAGGACCATCTTCTGCTCACT/ \\
& CGGAGTCTGTTCACTACCTTATTG \\
ALP & TGTGGAATACGAACTGGATGAG/ \\
& ATAGTGGGAATGCTGTGTCT \\
BSP & AAAATGGAGACGGCGATAGTT/ \\
& GAGTGTGGAAAGTGGGAGTTCT \\
Osx & GAAAGGAGGCACAAAGAAG/ \\
& CACCAAGGAGTAGGTGTGTT \\
3-catenin & GCAGTCTTACTTGGATTCTGGA/ \\
& AGCCTTGCTCCATTCATAA \\
DKK 1 & GAGGTCCCGAAGTTGAGGTT/ \\
& GCAGAGAGCCATCATTGTAAAC \\
TCF 1 & GGACTCACCCTCGTATCTTCTG/ \\
& TGTTGCTGTATCTGTGGATTCTG \\
GAPDH & GGAGATTGTTCCATCAACGA/ \\
& GAAGACACCAGTAGACTCCACGACA \\
\hline
\end{tabular}

\section{Western Blot}

After the cells were treated with $10 \mathrm{mM} \mathrm{LiCl}$ for $3,6,12,24 \mathrm{hr}$ or transfected for 36,46 and $72 \mathrm{hr}$ respectively, the protein was extracted. Cells were rinsed twice with ice-cold PBS and lysed with 100ul Mam- malian protein Extraction reagent (Thermo Scientific, China). The lysates were centrifuged for 15 minutes at $16,000 \times \mathrm{g}$ at $4^{\circ} \mathrm{C}$. Protein concentrations were determined using BCA Protein Assay Kit (Pierce). Total protein $(20 \mu \mathrm{g})$ was separated on $8 \%$ SDS-PAGE gels and transferred to PVDF membranes (Millipore). Five $\%$ milk in TBS containing $0.05 \%$ Tween- 20 was used to block non-specific binding for 60 minutes. These membranes were immunoblotted separately with anti-OSX (1:1000), anti- $\beta$-catenin (1:5000), anti-OCN (1:800), anti-OPN (1:1000), or anti-BSP (1:500) overnight at $4^{\circ} \mathrm{C}$. The membranes were washed three times ( $3 \times 5$ minutes) with TBS/0.05\% Tween-20 and then incubated with horseradish peroxidase-conjugated anti-rabbit secondary antibodies $(1: 10,000)$ for $1 \mathrm{~h}$. After another washing for $3 \times 5$ minutes, the membranes were detected with ECL Detection Reagents (Thermo Scientific) and exposed to x-ray film for detection of expression levels.

\section{Immunofluorescence and immunohistochem- istry assays}

An immunofluorescence assay was performed to assess nuclear translocation of $\beta$-catenin and the expression of OPN, OCN, BSP and ALP. OCCM-30 cells were washed in PBS at indicated times, and fixed with $4 \%$ paraformaldehyde for 30 minutes at room temperature followed by permeabilization with PBS containing $0.1 \%$ Triton X-100 for 5 minutes. The cells were then incubated in PBS containing 5\% BSA for 60 minutes at room temperature to block non-specific binding. Next, cells were incubated with anti- $\beta$-catenin (1:800), anti-OCN (1:200), anti-OPN (1:400), anti-BSP (1:100), or anti-ALP (1:50) overnight at $4^{\circ} \mathrm{C}$ and washed three times with PBS. Cells were subsequently incubated with goat anti-rabbit secondary antibody (1:500) for 60 minutes at $37^{\circ} \mathrm{C}$ and washed three times with PBS. After staining with DAPI (Invitrogen) for 2 minutes, cover slips were mounted with anti-fluorescence quench reagent (Beyotime). Pictures were taken under an inverted fluorescence microscope. Immunostained mouse jaws were previously described $(26,32)$. The Os $x$ conditional knockout (cKO, the crossing between Osx-LoxP (30) and the 2.3 Col 1-Cre (31) mice), and control samples were obtained from the previous studies, in which we reported a great loss of cementum and mineral deposition rates (26).

\section{Alkaline phosphatase activity assay}

The cells were plated at density of $5 \times 10^{4} /$ well in 48 -well plates. At $96 \mathrm{hr}$ after transfection or stimulation with $5 \mathrm{mM}$ or $10 \mathrm{mM} \mathrm{LiCl}$, the cells were washed three times with PBS, and then lysed with Mammalian protein Extraction reagent (Thermo Scientific) and 
centrifuged for 15 minutes at $16,000 \times \mathrm{g}$ at $4^{\circ} \mathrm{C}$. Five $\mu \mathrm{l}$ of supernatant was used to measure the protein content of each sample with BCA protein assay kit (Pierce). Thirty $\mu$ l of supernatant was used to determine the ALP activity with an ALP activity assay kit according to the manufacturer's instructions. The enzyme activity was reported as $\mathrm{U} / \mathrm{g}$ of protein.

\section{Alizarin Red Staining}

The OCCM-30 cells were plated in 12-well plates $\left(1 \times 10^{5} /\right.$ well $)$ and cultured in $5 \% \mathrm{CO}_{2}$ at $37^{\circ} \mathrm{C}$. Upon sub-confluence, the cells were replaced with or without $\mathrm{LiCl}$ and osteogenic medium containing $10 \mu \mathrm{M}$ $\mathrm{Na}$-glycerophosphate, $50 \mu \mathrm{g} / \mathrm{ml}$ ascorbic acid and $0.1 \mathrm{uM}$ dexamethasone. The medium was changed every 3 days. After 2 weeks, the cells were fixed with $95 \%$ ethanol, treated with $2 \%$ Alizarin red staining $(\mathrm{pH} 4.2)$ for $15 \mathrm{~min}$ at $37^{\circ} \mathrm{C}$, and then washed five times with PBS. After the photos of nodules were taken, $1 \mathrm{ml} \mathrm{10 \%} \mathrm{cetylpyridinium} \mathrm{chloride} \mathrm{was} \mathrm{added}$ into each well to dissolve the nodules, and the absorbance was examined at $562 \mathrm{~nm}$.

\section{Statistical Analysis}

Results were reported as mean $\pm S D$. The t-test and One-way ANOVA were used to evaluate statistical differences with GraphPad Prism 6. P<0.05 was considered statistically significant.

\section{RESULTS}

\section{Osx accelerates cementoblast differentiation}

To study the function of Osx in cementoblast differentiation in vitro, we initially took the gain of function approach by transient transfection of the CMV-Osx expression plasmid into the cementoblast cell line. The forced increase in Osx at mRNA and protein levels (Fig. 1a) led to significant increases in the mRNA (Fig. 1b) and protein (Fig. 1c) levels of OPN, OCN, and BSP, as well as ALP activity (Fig. 1d). To confirm these observations, we used the loss of function (siRNA) approach and knocked down $O s x$ mRNA and protein levels (Fig. 1e). As predicted, the down-regulation of $O s x$ resulted in sharp reductions in expression of the above cementoblast markers, including expression levels of OPN, OCN and ALP (Fig. 1f), and ALP activities (Fig. 1g). In addition, immunostained images displayed pronounced decreases in these markers in Osx knockdown cementoblasts (Fig. 1h). Taken together, the above data are in agreement with the in vivo studies, in which Osx is shown to be critical for cementum growth during postnatal development (26).

\section{Osx inhibits $W n t / \beta$-catenin signaling in ce- mentoblasts}

To understand the molecular mechanisms by which Osx controls cementoblast markers, we analyzed the expression of $\beta$-catenin responses to the overexpression or down-regulation of Osx. Unexpectedly, the forced expression of Osx inhibited $\beta$-catenin while knockdown of $O s x$ enhanced $\beta$-catenin levels as visualized by Western blot (Fig. 2a) and nuclear translocation by immunofluorescent assay (Fig. 2b). Further, we showed corresponding changes of Tcf1 expression by real time RT-PCR: overexpression of Osx significantly decreased Tcf1 whereas Osx knockdown increased Tcf1 expression (Fig. 2c). These experiments support the notion that Osx controls gene expression in cementoblasts by negative regulation of the $\beta$-catenin signaling pathway (i.e., maintaining a low level of $\beta$-catenin during cementoblast differentiation).

\section{Over-activation of $\mathrm{Wnt} / \beta$-catenin signaling by $\mathrm{LiCl}$ recaptures Osx knockdown effects on cementoblast differentiation}

To further test the above hypothesis, we examined the cellular effect of $\mathrm{LiCl}$, the GSK-3 $\beta$ inhibitor that prevents degradation of $\beta$-catenin in the cytoplasm, including the time-dependent influence of $\mathrm{LiCl}$ on $\beta$-catenin and TCF-1. As expected, $\beta$-catenin protein levels were increased after $3 \mathrm{~h}$ of treatment, with the peak increases at 12 and 24 hours (Supplementary Material: Fig. S1a). We found an increase in the nuclear translocation of $\beta$-catenin by immunofluorescence assay (Fig. S1b) and a time-dependent increase in Tcf-1 expression by real-time RT-PCR (Fig. S1c). Analysis of gene expression changes in Opn, Ocn and $B s p$, as well as ALP activity and the in vitro mineralization by $\mathrm{LiCl}$ at two dosages (5- and $10-\mathrm{mM}$ ) and two time points (24- and 36-hours) clearly showed that expression of these genes was suppressed in the cementoblast cell line treated with $\mathrm{LiCl}$ in a time- and dose-dependent manner (Fig. 3a). These observations were further supported by Western blot data (Fig. 3b), ALP activity (Fig. 3c) and Alizarin red stained mineralization studies (Fig. 3d). In summary, these in vitro results confirm the negative role of the $\beta$-catenin signaling pathway in the regulation of cementoblast differentiation and mineralization. 

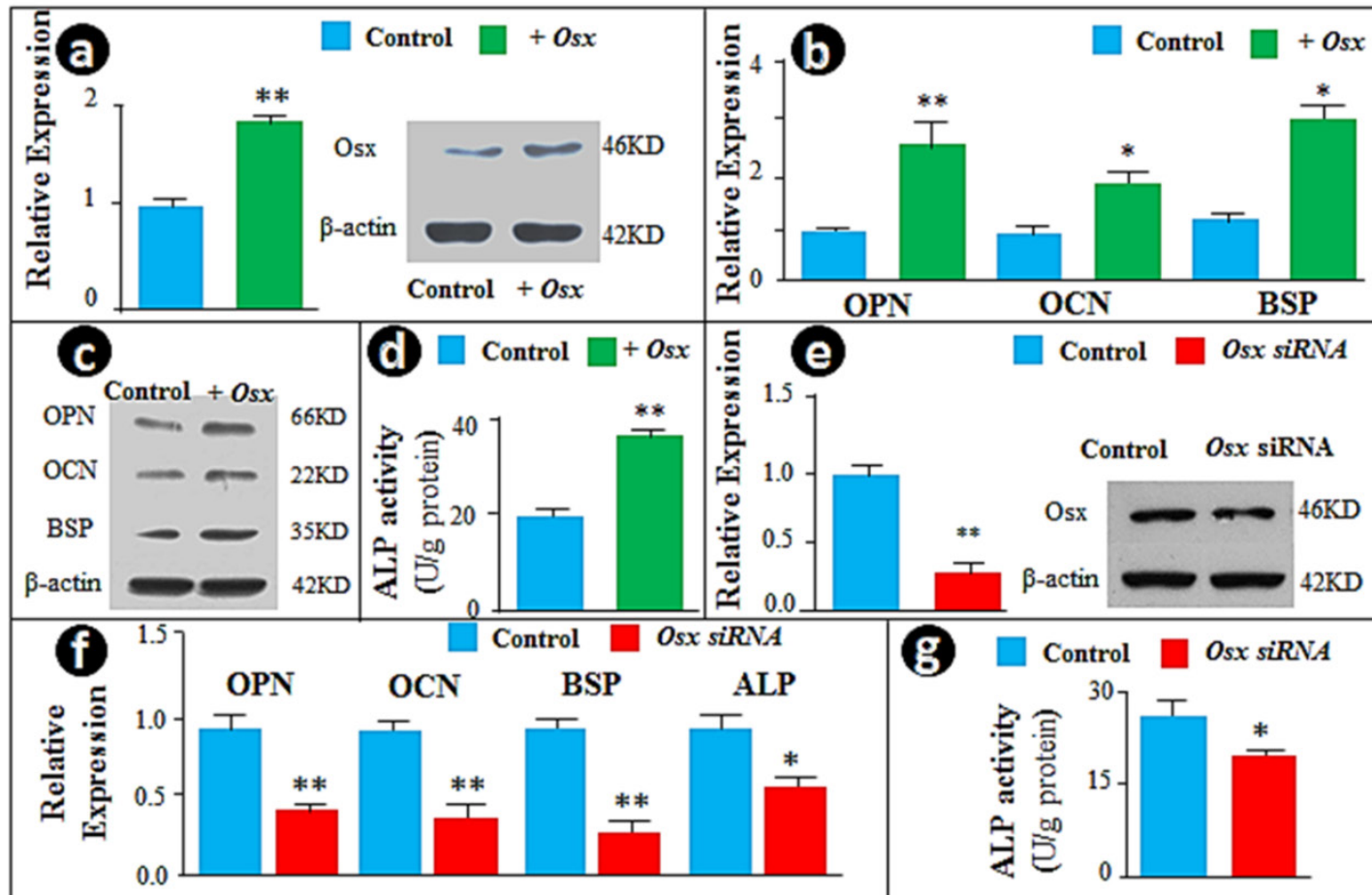

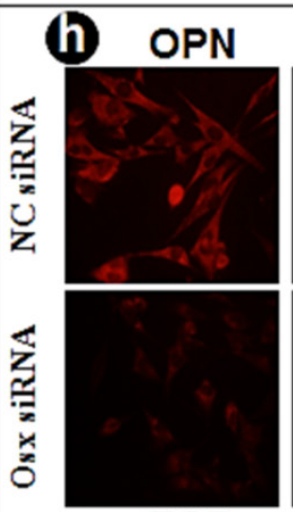

BSP
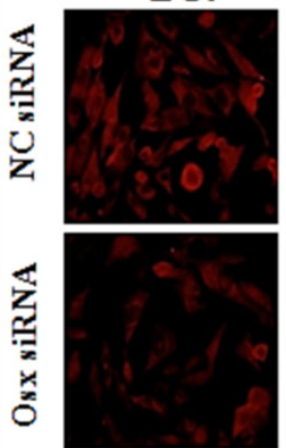

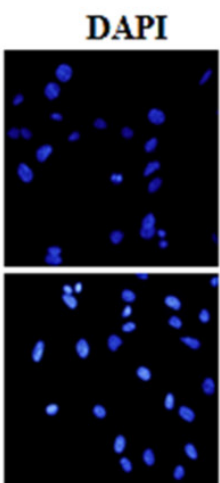

DAPI
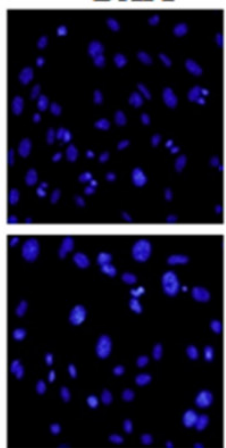

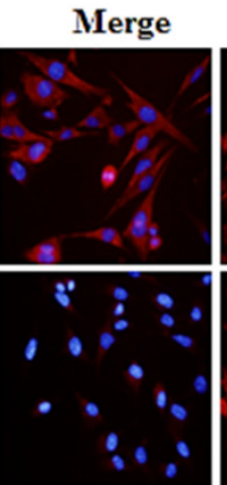

Merge
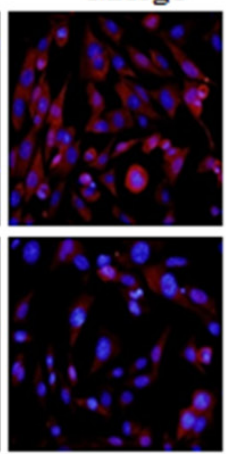

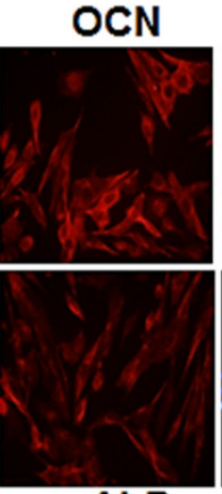

ALP
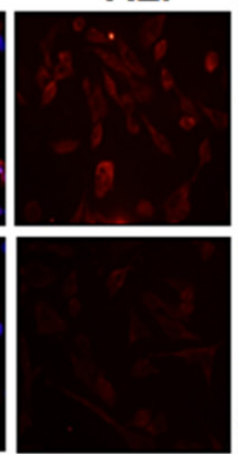

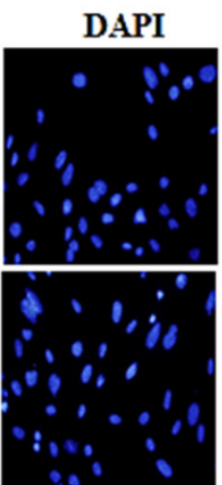

DAPI

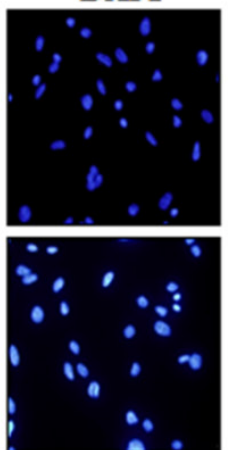

Merge

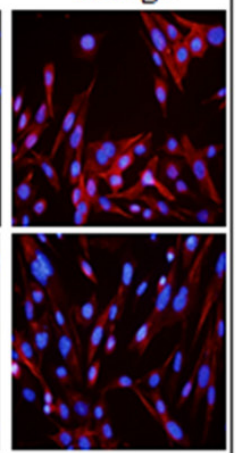

Merge
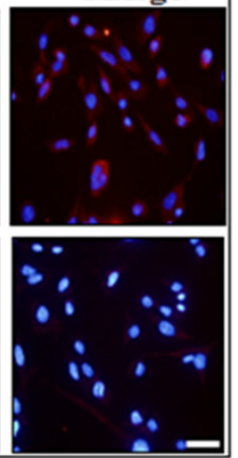

Figure 1. Overexpression of Osx accelerates but siRNA knock-down of Osx inhibits cementoblast differentiation in vitro. (a) The cementoblast cell lines (OCCM) were transfected with either CMV-Osx expression plasmids or the empty vector, and RT-PCR (left panel) and Western blot (right panel) were performed to evaluate whether an increase in Osx mRNA and protein levels occured after transient transfection of Osx (T Osx); (b-c) Cementoblast differentiation markers such as OPN, OCN, and BSP were increased in the experimental group (green) at mRNA levels (b) and protein levels (c) compared to the control group; (d) The ALP assay revealed an increase in ALP activity by overexpression of Osx; (e) The siRNA technique was used to knock-down Osx at levels of mRNAs and protein; (f) The mRNA and protein levels of OPN, OCN, BSP, and ALP, and were significantly reduced in the cell transfected with siRNA; $(g) A L P$ activity was significantly reduced in the treated group; and (h) The immunofluorescence staining images confirmed the above changes of OPN, OCN, BSP and ALP at the protein levels in the Osx knock-down group. The signal is in red and nuclear stain is blue. Scale bar, 10 4 m. Data represented as mean $\pm S D$ of three separate experiments with five wells each time. Statistical differences: $* P<0.05, * * P<0.01$. 


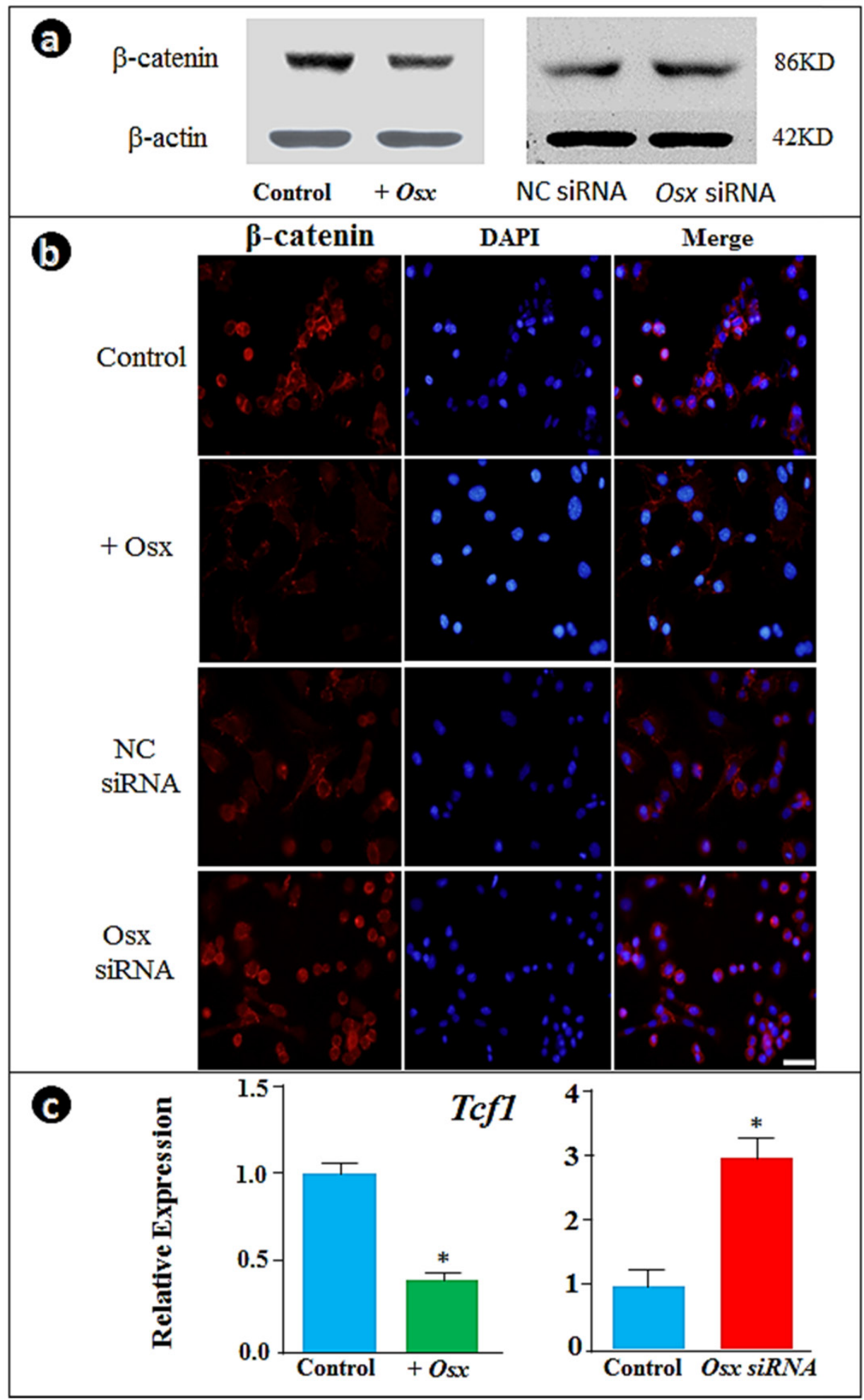

Figure 2. Overexpression of Osx inhibits and the Osx knock-down increases $\beta$-catenin signaling in cementoblasts. (a) The Western blot images showed that overexpression of $O s x$ leads to a reduction in $\beta$-catenin levels, whereas Osx knock-down results in an increase in $\beta$-catenin; (b) The immunofluorescence stain assay confirmed the above observation in the changes in $\beta$-catenin in the nucleus ( $\beta$-catenin signal, red; DAPI stained nucleus, blue; Scale bar, 10 $\mu \mathrm{m})$; and (c) The real-time RT-PCR data showed a down-regulation of Tcfl by overexpression of Osx and up-regulation by Osx siRNA. Data were represented as mean \pm SD of five wells each time with three separate experiments. Statistical differences: $* P<0.05$ 


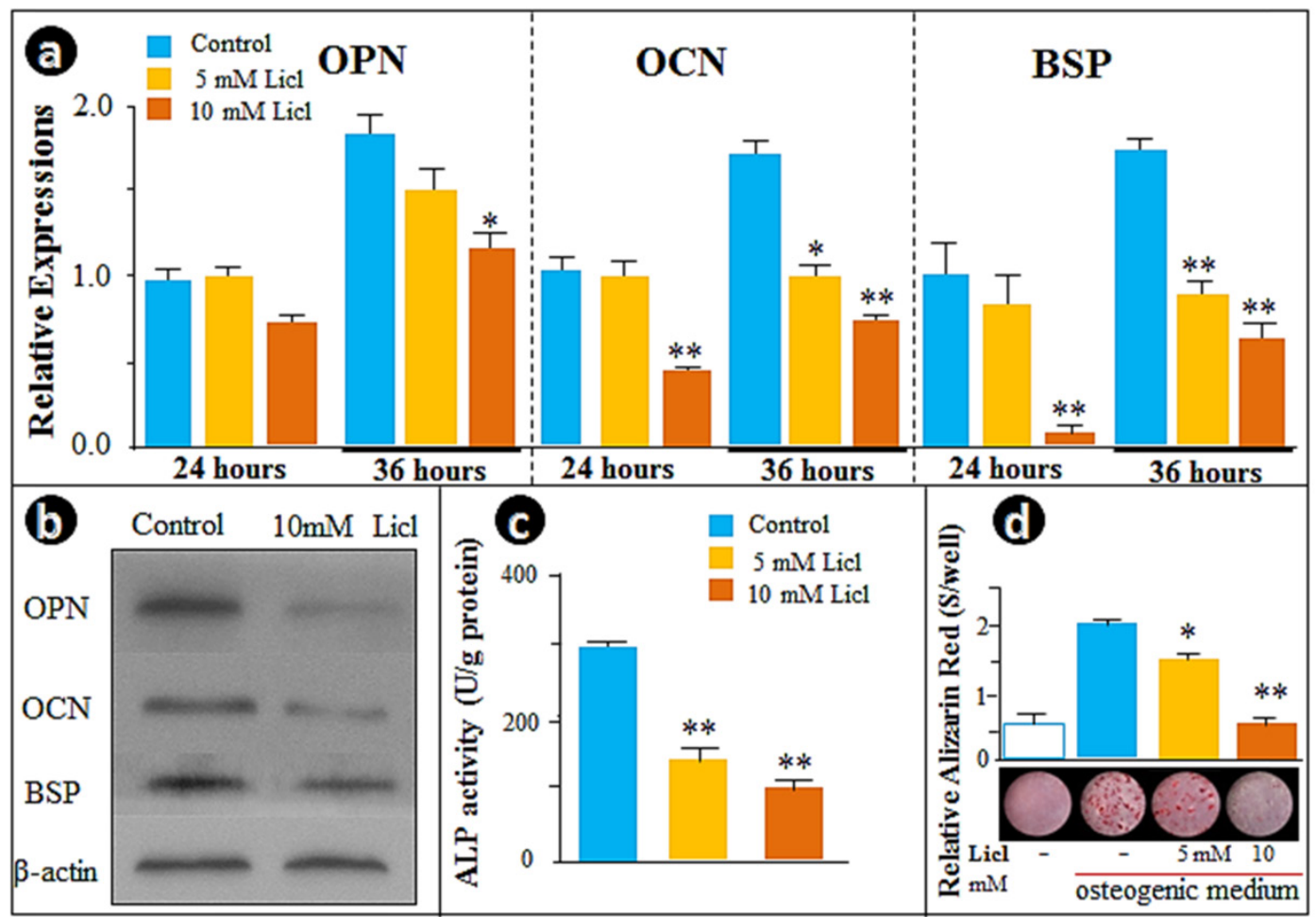

Figure 3. Activation of $\mathrm{Wnt} / \beta$-catenin signaling by $\mathrm{LiCl}$ recaptures the Osx knockdown effects on cementoblast differentiation. (a) The real-time $\mathrm{RT}$-PCR assays demonstrated a dose-dependent inhibition of the expression of OPN, OCN, and BSP in cells treated with 5-and 10-mMLiCl; (b)The Western blot images confirmed the inhibitions of OPN, OCN, and BSP at the protein levels; (c) The ALP assay showed a similar dose-dependent reduction of the enzyme activity; (d) The alizarin red-stained image (bottom) and semi-quantitative data based on color reaction (upper panel) demonstrated a dose-dependent reduction in mineralization. Data were represented as mean $\pm \mathrm{SD}$ of five wells each time with three separate experiments. Statistical differences: $* \mathrm{P}<0.05 ; * * \mathrm{P}<0.01$.

\section{Osx negatively controls the $\mathrm{Wnt} / \beta$-catenin signaling pathway by direct activation of DKK1, the potent inhibitor of $W n t / \beta$-catenin signaling, during cementoblast differentiation in vitro and in vivo}

Recent studies suggest that the Wnt/ $\beta$-catenin signaling negatively regulates cementogenic differentiation of adipose tissue-derived stem cells (33) or cementoblast differentiation (13) likely through the positive regulation of cementoblast cell differentiation by DKK1. Thus, we examined whether the negative regulation of the Wnt/ $\beta$-catenin signaling by Osx (Fig. 2) occurs via upregulation of DKK1 levels. Using transient transfection, we first showed that the forced expression of Osx significantly increased Dkk1 mRNA levels (Fig. 4a; >2.5-fold upregulation). We also demonstrated that $O s x$ knockdown resulted in over $50 \%$ inhibition in DKK1 expression, which was completely reversed either by large of amount of recombinant Wnt3a or DKK1 (Fig. 4b). In addition, we confirmed that recombinant Wnt3a activates the nuclear translocation of $\beta$-catenin (Supplementary Material: Fig. S2a and c) and Tcf-1 expression (Fig. S2b). As a result, mRNA (Fig. S2d) and protein (Fig. S2e) levels of cementoblast markers such as OPN, OCN, and BSP were reduced, concurrent with a 50\% ALP activity reduction (Fig. S2f). Once again, all of these changes induced by Wnt3a were significantly blocked by pre-treatment with recombinant DKK1 (Fig. S2), supporting the key function of OSX in maintaining a low level of Wnt/ $\beta$-catenin via enhancement of DKK1 expression in cementoblasts (Fig. 4c).

Because Osx-lacZ signal, reflecting the endogenous Osx expression level, is highly expressed in dental follicles (DF), the PDL, and bone cells (Fig. 4d), we tested DKK1 and $\beta$-catenin levels in the Osx cKO (crossing Osx floxed and 2.3 Col 1-Cre) mice. The immunostaining data revealed a sharp reduction in DKK1 (Fig. 4f) and a concurrent increase in $\beta$-catenin expression (Fig. 4f) in the DF and PDL, as well as in the odontoblasts $(\mathrm{Od})$. Similarly, the same change pattern occurred in the Osx cKO bone tissues (Supplementary Material: Fig. S3), further supporting our working hypothesis that OSX controls cementogenesis in part through the Wnt- $\beta$-catenin signaling pathway via an up-regulation of DKK1 (Fig. 4c).

\section{DISCUSSION}

Postnatal cementum development requires the integration of multiple transcription factors and signaling molecules, including OSX and Wnt. It is clear that OSX is essential for cementogenesis based on a close relationship between a temporal- and spa- 
tial-expression pattern of $O s x$ and formation of cellular cementum plus the gain- and loss-function studies (26), although the molecular mechanisms by which OSX controls cellular cementoblasts remain uncertain. In this study, we used multiple techniques combining both in vitro and in vivo models, and demonstrated that during cementogenesis OSX negatively controls the Wnt- $\beta$-catenin signaling pathway via up-regulation of DKK1 to maintain a low level of Wnt- $\beta$-catenin during cementogenesis.

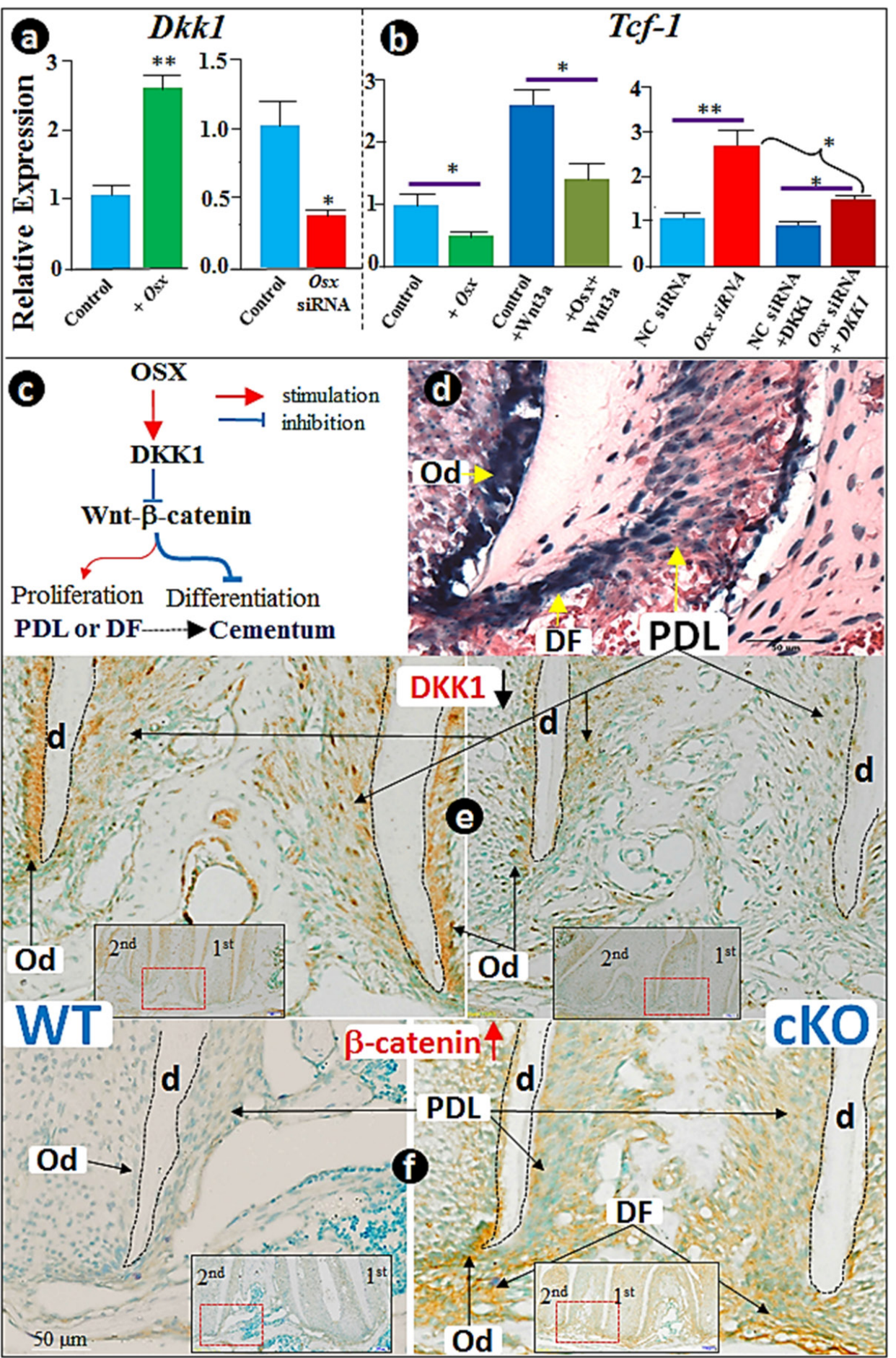

Figure 4. The negative regulation of $\mathbf{W n t} / \boldsymbol{\beta}$-catenin by OSX is in part through activation of DKK1. (a) The RT-PCR analysis revealed that overexpression of Osx leads to up-regulation of Dkkl (left panel), and that Osx siRNA transfection results in a sharp reduction of Dkkl (right panel); (b) The RT-PCR analysis showed that overexpression of Osx leads to down-regulation of Tcf-I (left panel), and partially reverses the positive reaction of Tcf-I in response to Wnt3 (right panel); (c) The diagram summarizes the in vitro findings: OSX negatively regulates Wnt- $\beta$-catenin through activation of DKK1, the potent inhibitor of Wnt signaling; (d) The $x$-gal-stained image revealed the expression pattern of Osx-lacZ in dental follicles (DF), periodontal ligament (PDL), bone cells, and odontoblast (Od); (e) Immunostain images demonstrated a great reduction in the Osx cKO PDL and Od cells (right panel; red and black arrows); (f) Immunostained images revealed a sharp increase in $\beta$-catenin in the Osx cKO PDL and Od cells (right panel). Data represented as mean $\pm S D$ of five wells each time with three separate experiments. Statistical differences: $* \mathrm{P}<0.05 ; * * \mathrm{P}<0.01$ 
The Wnt- $\beta$-catenin signaling pathway is essential for almost all organ development, including tooth (34). However, the role of Wnt- $\beta$-catenin signaling in cementogenesis is controversial. For example, Lim and colleagues showed that cementum is thicker in a genetic strain of mice in which Wnt signaling is elevated (35). Similarly, Cho's lab reported an increase in cementum mass in mice with excessive Wnt- $\beta$-catenin $(36,37)$. Further, Kuchler and colleagues reported an increased thickness of the cementum and a concomitant moderate decrease in the periodontal space width in Sost KO mice (17). On the other hand, Nemoto and colleagues reported that in the cementoblast cell line Wnt signaling inhibits cementoblast differentiation and promotes proliferation (13). Liu and colleagues showed that DKK1 stimulates but Wnt3 inhibits cementoblast differentiation of adipose tissue-deprived stem cells (38). It is important to note that none of these groups compared the role of Wnt- $\beta$-catenin in cementum both in vivo and in vitro.

To better address the mechanism by which OSX controls cementogenesis through the Wnt- $\beta$-catenin pathway, we first used in vitro approaches (Figs. 1-4) and confirmed that Wnt3a or $\mathrm{LiCl}$ indeed inhibits the expression of OPN, OCN, and BSP mRNA and protein levels, and reduces ALP activity and formation of mineralized nodules in cementoblasts. We next demonstrated that OSX enhances cementoblast differentiation but inhibits cell proliferation via reducing Wnt signaling pathway in cementoblasts, which is supported by the following evidence: 1) overexpression of Osx reduced $\beta$-catenin protein level; 2 ) inhibition of Osx expression by siRNA led to a strong nuclear translocation of $\beta$-catenin; and 3) overexpression of $O s x$ decreased the transcriptional activity of TCF-1 by over $50 \%$.

To explore the link between OSX and the Wnt signaling pathway, we identified the key role of DKK1 in bridging the WNT signaling and OSX function based on the following findings: overexpression of Osx leads to a significant decrease in the mRNA level of Dkk1, whereas knock-down of Osx results in an increase in Dkk1 levels. Furthermore, we showed that addition of DKK1 to the culture medium partially reversed the negative regulation of WNT signaling in cementoblast differentiation. Finally, we re-examined the $O s x$ cKO lower jaw we previously reported (26), and demonstrated that the sharp reduction in DKK1 expression in $O s x$ cKO is directly correlated with a great increase in $\beta$-catenin expression (Fig. 4 and Supplementary Material: Fig. S3).

It is well documented that OSX, as a zinc finger-containing transcription factor, plays an essential role in osteoblast differentiation $(19,24)$, and that cementoblasts share phenotypical characteristics with osteoblasts in many aspects, such as expressing the common gene markers such as OPN, ALP, and OCN $(3,4,39)$. Furthermore, OSX has been shown to down-regulate the canonical Wnt signaling pathway by activating DKK1 in bone cells (21). A recent study also showed that OSX can synchronously work with HIF-1a to further inhibit $\beta$-catenin activity (40). Given the common features between cementoblasts and osteoblasts plus the similar regulation mechanism as that reported for the osteoblasts $(6,41)$, we propose that Wnt- $\beta$-catenin signaling must be kept a low level in cementoblasts during postnatal development, because a high level of Wnt- $\beta$-catenin signaling will lead to a greater mass of immature cementum due to an increase in cell proliferation coupled with a decrease in cell differentiation (Fig. 4c). This hypothesis seems in contrast to the promotion of the quiescence-to-proliferation switch by the Wnt signaling pathway in the early cementogenesis. However, we believe that this biphasic role of Wnt signaling during cementogenesis is essential. For example, in the early stage (i.e. before cementoblast formation), Wnt- $\beta$-catenin represses the quiescence-to-proliferation switch in early progenitor cells. In the late stage (i.e. during cementum formation), Wnt- $\beta$-catenin signaling must be kept at a low level, which will ensure the proliferation-to-differentiation transition. This may explain why the expanded cementum in the CA- $\beta$-catenin model is thicker but not fully matured (35).

In summary, we report for the first time OSX regulates the differentiation of cementoblasts by maintaining a low level of $\mathrm{Wnt} / \beta$-catenin signaling via a positive regulation of DKK1. This finding will enhance our understanding of the regulation of Wnt- $\beta$-catenin signaling by OSX during cementogenesis. Although the current finding and interpretation is based on studies in cementoblasts, this model might be applied to other hard tissues such as bone and dentin.

\section{Supplementary Material}

Fig.S1 - Fig.S3.

http://www.ijbs.com/v11p0335s1.pdf

\section{Acknowledgements}

The study was supported by grants from the National Natural Science Foundation of China to ZC (81170933), and NIH/NIDCR grants to JQF (DE018486 and DE022789) and to SPH/JQF (DE022032). The authors gratefully acknowledge Jingya Wang for her excellent technique work on histological work, and Dr. Yinghong Zhou from Queensland University of Technology for her great suggestions and thorough reviewing of this paper. 


\section{Competing Interests}

The authors have declared that no competing interest exists.

\section{References}

1. Kassebaum NJ, Bernabe E, Dahiya M, Bhandari B, Murray CJ, and Marcenes W. Global Burden of Severe Periodontitis in 1990-2010: A Systematic Review and Meta-regression. J Dent Res. 2014;93(11):1045-53.

2. Grzesik WJ, and Narayanan AS. Cementum and periodontal wound healing and regeneration. Crit Rev Oral Biol Med. 2002;13(6):474-84.

3. D'Errico JA, MacNeil RL, Takata T, Berry J, Strayhorn C, and Somerman MJ. Expression of bone associated markers by tooth root lining cells, in situ and in vitro. Bone. 1997;20(2):117-26.

4. Bosshardt DD. Are cementoblasts a subpopulation of osteoblasts or a unique phenotype? J Dent Res. 2005;84(5):390-406.

5. Kitagawa M, Tahara H, Kitagawa S, Oka H, Kudo Y, Sato S, Ogawa I, Miyaichi $\mathrm{M}$, and Takata T. Characterization of established cementoblast-like cell lines from human cementum-lining cells in vitro and in vivo. Bone. 2006;39(5):1035-42.

6. Hirata A, Sugahara T, and Nakamura H. Localization of runx2, osterix, and osteopontin in tooth root formation in rat molars. J Histochem Cytochem. 2009;57(4):397-403

7. Logan CY, and Nusse R. The Wnt signaling pathway in development and disease. Annual review of cell and developmental biology. 2004;20:781-810.

8. Miller JR. The Wnts. Genome biology. 2002;3(1):REVIEWS3001.

9. Huelsken J, and Behrens J. The Wnt signalling pathway. Journal of cell science. 2002;115(Pt 21):3977-8

10. Heo JS, Lee SY, and Lee JC. Wnt/beta-catenin signaling enhances osteoblastogenic differentiation from human periodontal ligament fibroblasts. Molecules and cells. 2010;30(5):449-54.

11. Han $\mathrm{P}, \mathrm{Wu} \mathrm{C}, \mathrm{Chang} \mathrm{J}$, and Xiao $\mathrm{Y}$. The cementogenic differentiation of periodontal ligament cells via the activation of Wnt/beta-catenin signalling pathway by $\mathrm{Li}+$ ions released from bioactive scaffolds. Biomaterials. 2012;33(27):6370-9.

12. Zhang $R$, Yang $G$, Wu $X$, Xie J, Yang $X$, and Li T. Disruption of Wnt/beta-catenin signaling in odontoblasts and cementoblasts arrests tooth root development in postnatal mouse teeth. International journal of biological sciences. 2013;9(3):228-36.

13. Nemoto E, Koshikawa Y, Kanaya S, Tsuchiya M, Tamura M, Somerman MJ, and Shimauchi $\mathrm{H}$. Wnt signaling inhibits cementoblast differentiation and promotes proliferation. Bone. 2009;44(5):805-12.

14. Rooker SM, Liu B, and Helms JA. Role of Wnt signaling in the biology of the periodontium. Developmental dynamics : an official publication of the American Association of Anatomists. 2010;239(1):140-7.

15. Lehnen SD, Gotz W, Baxmann M, and Jager A. Immunohistochemical evidence for sclerostin during cementogenesis in mice. Annals of anatomy = Anatomischer Anzeiger : official organ of the Anatomische Gesellschaft. 2012;194(5):415-21.

16. Jager A, Gotz W, Lossdorfer S, and Rath-Deschner B. Localization of SOST/sclerostin in cementocytes in vivo and in mineralizing periodontal ligament cells in vitro. Journal of periodontal research. 2010;45(2):246-54.

17. Kuchler U, Schwarze UY, Dobsak T, Heimel P, Bosshardt DD, Kneissel M, and Gruber R. Dental and periodontal phenotype in sclerostin knockout mice. International journal of oral science. 2014;6(2):70-6.

18. van Bezooijen RL, Bronckers AL, Gortzak RA, Hogendoorn PC, van der Wee-Pals L, Balemans W, Oostenbroek HJ, Van Hul W, Hamersma H, Dikkers FG, et al. Sclerostin in mineralized matrices and van Buchem disease. J Dent Res. 2009;88(6):569-74.

19. Nakashima K, Zhou X, Kunkel G, Zhang ZP, Deng JM, Behringer RR, and de Crombrugghe $\mathrm{B}$. The novel zinc finger-containing transcription factor Osterix is required for osteoblast differentiation and bone formation. Cell. 2002;108(1):17-29.

20. Nishio $\mathrm{Y}$, Dong $\mathrm{Y}$, Paris $\mathrm{M}$, O'Keefe RJ, Schwarz EM, and Drissi $\mathrm{H}$. Runx2-mediated regulation of the zinc finger Osterix/Sp7 gene. Gene. 2006;372:62-70.
21. Zhang C, Cho KC, Huang YH, Lyons JP, Zhou X, Sinha K, McCrea PD, and de Crombrugghe $\mathrm{B}$. Inhibition of Wnt signaling by the osteoblast-specific transcription factor Osterix. Proceedings of the National Academy of Sciences of the United States of America. 2008;105(19):6936-41.

22. Fu H, Doll B, McNelis T, and Hollinger JO. Osteoblast differentiation in vitro and in vivo promoted by Osterix. Journal of biomedical materials research Part A. 2007;83(3):770-8

23. Baek WY, Lee MA, Jung JW, Kim SY, Akiyama H, de Crombrugghe B, and Kim JE. Positive regulation of adult bone formation by osteoblast-specific transcription factor osterix. J Bone Miner Res. 2009;24(6):1055-65.

24. Zhang C. Transcriptional regulation of bone formation by the osteoblast-specific transcription factor Osx. Journal of orthopaedic surgery and research. 2010;5:37.

25. Jing J, Hinton RJ, Jing Y, Liu Y, Zhou X, and Feng JQ. Osterix Couples Chondrogenesis and Osteogenesis in Post-natal Condylar Growth. J Dent Res. 2014;93(10):1014-21.

26. Cao Z, Zhang H, Zhou X, Han X, Ren Y, Gao T, Xiao Y, de Crombrugghe B, Somerman MJ, and Feng JQ. Genetic evidence for the vital function of Osterix in cementogenesis. J Bone Miner Res. 2012;27(5):1080-92.

27. Kim JY, Kim BI, Jue SS, Park JH, and Shin JW. Localization of osteopontin and osterix in periodontal tissue during orthodontic tooth movement in rats. Angle Orthod. 2012;82(1):107-14

28. D'Errico JA, Berry JE, Ouyang H, Strayhorn CL, Windle JJ, and Somerman MJ. Employing a transgenic animal model to obtain cementoblasts in vitro. J Periodontol. 2000;71(1):63-72.

29. Nakashima K, Zhou X, Kunkel G, Zhang Z, Deng JM, Behringer RR, and de Crombrugghe $\mathrm{B}$. The novel zinc finger-containing transcription factor osterix is required for osteoblast differentiation and bone formation. Cell. 2002;108(1):17-29.

30. Akiyama H, Kim JE, Nakashima K, Balmes G, Iwai N, Deng JM, Zhang Z, Martin JF, Behringer RR, Nakamura T, et al. Osteo-chondroprogenitor cells are derived from Sox9 expressing precursors. Proc Natl Acad Sci U S A. 2005;102(41):14665-70.

31. Liu F, Woitge HW, Braut A, Kronenberg MS, Lichtler AC, Mina M, and Kream BE. Expression and activity of osteoblast-targeted Cre recombinase transgenes in murine skeletal tissues. Int J Dev Biol. 2004;48(7):645-53.

32. Han XL, Liu M, Voisey A, Ren YS, Kurimoto P, Gao T, Tefera L, Dechow P, Ke HZ, and Feng JQ. Post-natal effect of overexpressed DKK1 on mandibular molar formation. J Dent Res. 2011;90(11):1312-7.

33. Silva-Garcia O, Valdez-Alarcon JJ, and Baizabal-Aguirre VM. The Wnt/-Catenin Signaling Pathway Controls the Inflammatory Response in Infections Caused by Pathogenic Bacteria. Mediators of inflammation. 2014;2014:310183.

34. Liu F, Chu EY, Watt B, Zhang Y, Gallant NM, Andl T, Yang SH, Lu MM, Piccolo S, Schmidt-Ullrich R, et al. Wnt/beta-catenin signaling directs multiple stages of tooth morphogenesis. Developmental biology. 2008;313(1):210-24.

35. Lim WH, Liu B, Hunter DJ, Cheng D, Mah SJ, and Helms JA. Downregulation of Wnt causes root resorption. Am J Orthod Dentofacial Orthop. 2014;146(3):337-45.

36. Bae CH, Lee JY, Kim TH, Baek JA, Lee JC, Yang X, Taketo MM, Jiang R, and Cho ES. Excessive Wnt/ beta-catenin signaling disturbs tooth-root formation. J Periodontal Res. 2013;48(4):405-10.

37. Kim TH, Lee JY, Baek JA, Lee JC, Yang X, Taketo MM, Jiang R, and Cho ES. Constitutive stabilization of ss-catenin in the dental mesenchyme leads to excessive dentin and cementum formation. Biochem Biophys Res Commun. 2011;412(4):549-55

38. Liu N, Gu B, Liu N, Nie X, Zhang B, Zhou X, and Deng M. Wnt/beta-catenin pathway regulates cementogenic differentiation of adipose tissue-deprived stem cells in dental follicle cell-conditioned medium PLoS One. 2014;9(5):e93364.

39. Bosshardt DD, Zalzal S, McKee MD, and Nanci A. Developmental appearance and distribution of bone sialoprotein and osteopontin in human and rat cementum. Anat Rec. 1998;250(1):13-33.

40. Chen D, Li Y, Zhou Z, Xing Y, Zhong Y, Zou X, Tian W, and Zhang C. Synergistic inhibition of Wnt pathway by HIF-1alpha and osteoblast-specific transcription factor osterix (Osx) in osteoblasts. PloS one. 2012;7(12):e52948.

41. Kim BI, Na SH, Kim JY, Shin JW, and Jue SS. Immunolocalization of Runx2 and Osterix in the Developing Periodontal Tissues of the Mouse. International Journal of Oral Biology. 2011;36(2):51-7. 